Revista ACB: Biblioteconomia em Santa Catarina, Florianópolis, v. 22, n. 2, ESPECIAL, p. 180-191, abr./ jul., 2017. Anais do $35^{\circ}$ Painel Biblioteconomia Santa Catarina.

Chapecó

Recebido em: 13-03-2017 Aceito em: 05-05-2017

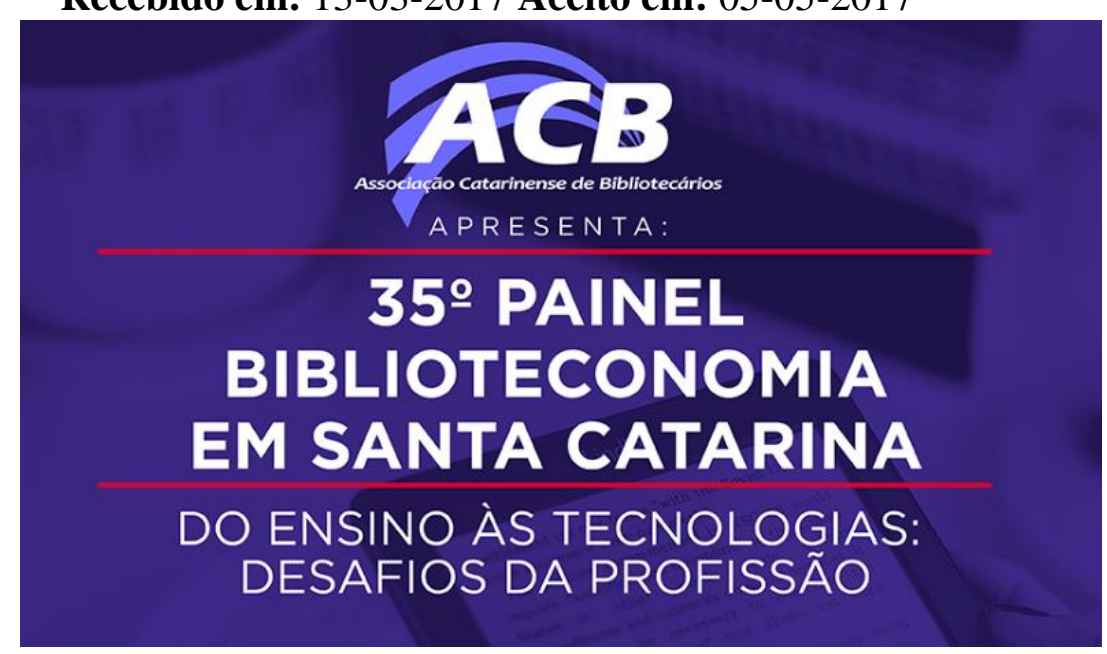

\title{
A AÇÃo CULTURAL NAS BIBLIOTECAS E SUA DIMENSÃo PARA A SOCIEDADE DO SÉCULO XXI
}

\author{
Criselen Jarabiza ${ }^{1}$ \\ Carla Rosane da Silva Tavares Alves ${ }^{2}$
}

\begin{abstract}
Resumo: Este texto objetiva discutir a ação cultural em uma perspectiva emancipatória, convergindo as discussões para os estudos culturais, sociedade da informação, era da cibercultura e do ciberespaço, interligando o ambiente físico e digital. Também tem como objetivo verificar se os cursos de Biblioteconomia do Rio Grande do Sul estão preparando os futuros bibliotecários para atuarem como agentes culturais. A metodologia utilizada nesta pesquisa é de abordagem qualitativa, do tipo exploratório, de caráter bibliográfico e análise documental das matrizes curriculares dos cursos de Biblioteconomia do RS. Foi constatado que as cinco instituições estão ofertando a disciplina de ação cultural, mesmo que com denominações diferentes. Assim, chegou-se à conclusão de que há uma visão por parte dos cursos pesquisados a respeito da necessidade da disciplina para a formação do futuro bibliotecário, e as ações culturais podem ser realizadas e publicizadas, utilizando-se das tecnologias da informação e comunicação.
\end{abstract}

Palavras-chave: Ação cultural. Bibliotecas. Cibercultura. Currículo.

\section{INTRODUÇÃO}

O presente artigo busca analisar a importância social da ação cultural, nas bibliotecas da atualidade, pois se vive um período denominado "era da informação", no qual as máquinas e redes de computadores têm possibilitado o acesso remoto a todo o tipo de informações, funcionando como uma gigante biblioteca em que a informação precisa ser selecionada e filtrada pelo usuário, obtendo, assim, o que ele realmente necessita.

Com o advento da internet, surge a cibercultura que é um processo de mutação da vida em sociedade. Hoje, mudam-se as formas de trabalhar, de relacionar-se, de ter sociabilidade, de acesso à informação, proporcionadas pela existência do ciberespaço. Segundo Levy (1999, p. 111), “Quanto mais

\footnotetext{
${ }^{1}$ Mestranda em Práticas Socioculturais e Desenvolvimento Social pela Universidade de Cruz Alta (UNICRUZ).

2 Doutora em Letras pela Universidade Federal do Rio Grande do Sul (UFRGS).

Revista ACB: Biblioteconomia em Santa Catarina, Florianópolis (Brasil) - ISSN 1414-0594
} 
Revista ACB: Biblioteconomia em Santa Catarina, Florianópolis, v. 22, n. 2, ESPECIAL, p. 180-191, abr./ jul., 2017. Anais do $35^{\circ}$ Painel Biblioteconomia Santa Catarina.

Chapecó

o ciberespaço se amplia, mais ele se torna 'universal', e menos o mundo informacional se torna totalizável. O universal da cibercultura não possui nem centro, nem linha diretriz."

Nesse contexto, as bibliotecas exercem, ou deveriam exercer um papel mais dinâmico, saindo da "caixa", ou seja, oferecendo serviços e produtos pela internet, nas redes sociais, como Facebook, Twitter, nos aplicativos de comunicação como WhatsApp, sites, blogs, disponibilizando seu catálogo on-line e, em alguns casos, esses com acesso a obras na íntegra.

A ação cultural, através da arte e da cultura, faz parte deste momento em que as bibliotecas buscam integração com a sociedade. Flusser (1983) caracteriza a ação cultural como emergente e libertadora. Segundo o dicionário de Borba (2011, p. 475), “emergente que emerge ou surge num determinado momento, que se desenvolve ou se destaca repentinamente; ascendente." Libertador de acordo com o dicionário, Borba (2011, p. 840), “que liberta, que dá liberdade, que torna livre”. Eis a grande relevância da ação cultural, na qual os sujeitos da cultura podem se expressar livremente, sendo libertados e ascendendo como protagonistas.

Buscando saber a relevância da ação cultural enquanto prática sociocultural nos ambientes formativos dos estudantes de Biblioteconomia, cabe o seguinte questionamento sobre currículo: a ação cultural está presente, enquanto disciplina, nos cursos de Biblioteconomia do Rio Grande do Sul? Este questionamento é pertinente, pois se acredita que muitos bibliotecários vão se deparar com demandas relacionadas à cultura no mercado de trabalho, seja em bibliotecas, ou em outros centros de informação, havendo necessidade de atuação, por parte desses profissionais, como produtores e mediadores culturais.

Nesse sentido, foi realizada uma pesquisa nas matrizes curriculares de Biblioteconomia, das cinco instituições que oferecem o curso no Rio Grande do Sul: Universidade Federal do Rio Grande do Sul (UFRGS), Fundação Universidade Federal do Rio Grande (FURG), Centro Universitário Claretiano (CEUCLAR), Universidade de Caxias do Sul (UCS), Universidade Salgado de Oliveira (UNIVERSO), com o intuito de verificar se faz parte da matriz curricular de formação dos bibliotecários a Disciplina de Ação Cultural ou semelhante.

A metodologia utilizada nesta pesquisa é de abordagem qualitativa, do tipo exploratório, de caráter bibliográfico para construção do referencial teórico. Também foi realizada a análise documental das matrizes curriculares das cinco instituições citadas que oferecem o curso de Biblioteconomia, no RS. A pesquisa da documentação dos cursos iniciou pela consulta no E-mec ${ }^{3}$, para verificar quais são os cursos de Biblioteconomia no RS e acesso aos sites dos cursos e suas matrizes curriculares e, após a coleta de dados, foi realizada a mensuração e análise dos mesmos.

\footnotetext{
${ }^{3}$ Sistema de cadastro das instituições de ensino superior do Brasil e tem como finalidade a tramitação dos processos de regulamentação pela internet. As instituições de ensino superior fazem o credenciamento, buscam autorização, reconhecimento e renovação de reconhecimento de cursos.

Revista ACB: Biblioteconomia em Santa Catarina, Florianópolis (Brasil) - ISSN 1414-0594
} 
Revista ACB: Biblioteconomia em Santa Catarina, Florianópolis, v. 22, n. 2, ESPECIAL, p. 180-191, abr./ jul., 2017. Anais do $35^{\circ}$ Painel Biblioteconomia Santa Catarina.

Chapecó

\section{CULTURA, CibERCULTURA E AÇÃO CULTURAL}

A espécie humana, desde os primórdios, tem uma riqueza inestimável em se tratando de diversidade cultural, e essa diversidade da cultura permeia todos os espaços de ocupação humana, sendo imprescindível, para a pesquisa que se pretende desenvolver, a busca da conceituação de cultura e averiguar a sua influência, enquanto comportamento social.

A definição de cultura na visão de Tylor ${ }^{4}$ (1924) apud Toscano $(2010$, p. 44) mostra que cultura é “[...] aquele todo complexo que inclui conhecimento, crença, arte, moral, costumes e quaisquer outras capacidades e hábitos adquiridos pelo homem enquanto membro da sociedade.” Sendo a cultura um fruto da vida humana e da coletividade, os costumes e tradições, mesmo enraizados na práxis, ainda assim, estão em constante mudança em decorrência da passagem do tempo.

O conceito de cultura é dotado de um caráter genérico, sendo que o homem adquiriu conhecimento das ciências e das inovações tecnológicas que são capazes de proporcionar bem-estar, saúde e realização de seus desejos, ou seja, a aquisição cultural, de acordo com Freud (2010, p. 87) “A palavra 'cultura' designa a soma total de realizações e disposições pelas quais a nossa vida se afasta de nossos antepassados animais, sendo que tais realizações e disposições servem a dois fins: a proteção do homem contra a natureza e a regulamentação das relações dos homens entre si.”

Existem duas concepções básicas de cultura, segundo Santos (2006, p. 24): “A primeira concepção de cultura remete a todos os aspectos de uma realidade social; a segunda refere-se mais especificamente ao conhecimento, às ideias e crenças de um povo." A primeira concepção fala dos povos e sua organização social, como por exemplo, cultura brasileira, cultura camponesa, referindo-se a distintas realidades sociais.

Na segunda concepção, a realidade social continua presente, acrescida de uma especificidade no que se refere ao conhecimento, ideias e crenças, língua, literatura, conhecimento filosófico e artístico. Ambas as concepções somadas corroboram para o entendimento da cultura como sendo ativa passível de modificações, constantemente. O conceito de cultura, para Santos (2006) está de acordo com o pensamento de Bauman (2012, p. 296):

A cultura humana, longe de ser a arte da adaptação, é a mais audaciosa de todas as tentativas de quebrar os grilhões da adaptação como obstáculo fundamental à plena revelação da criatividade humana. A cultura, sinônimo da existência especificamente humana, é um audacioso movimento a fim de que o ser humano se liberte da necessidade e conquiste a liberdade para criar [...].

Bauman conceitua cultura como uma conquista da liberdade, da criação, da criatividade; Flusser (1983) traz a reflexão da biblioteca enquanto instrumento de ação cultural, situando a questão na

${ }^{4}$ TYLOR, E. B. Primitive culture. 7.ed. Nova York: Bretano, 1924, p. 1.

Revista ACB: Biblioteconomia em Santa Catarina, Florianópolis (Brasil) - ISSN 1414-0594 
Revista ACB: Biblioteconomia em Santa Catarina, Florianópolis, v. 22, n. 2, ESPECIAL, p. 180-191, abr./ jul., 2017. Anais do $35^{\circ}$ Painel Biblioteconomia Santa Catarina.

Chapecó

biblioteca, sugerindo que os profissionais da área se aprofundem no tema. Inicialmente, o autor traz à cultura dois conceitos: "Ou cultura é considerada como sendo o conjunto de objetos, obras, coisas feitas pelo homem, ou então como sendo a sua visão de mundo, conjunto de suas práticas sociais ou individuais" (FLUSSER, 1983, p.147).

Conforme o pensamento do antropólogo Laraia (1986), sem a difusão da cultura não seria possível o grande desenvolvimento da humanidade, pois os empréstimos que são feitos da criação de outros povos possibilitam desenvolvimento, evolução ao homem moderno. O autor afirma: "Não resta dúvida que grande parte dos padrões culturais de um dado sistema não foram criados por um processo autóctone, foram copiados de outros sistemas culturais. A esses empréstimos culturais a antropologia denomina de difusão" (LARAIA, 1986, p.105).

A cultura é o resultado da transformação do homem na natureza, então tudo que é cultural não é natural, ou seja, uma pedra será cultura quando for lapidada, pintada ou sofrer alguma modificação pela ação do homem, definida como criação cultural, como destaca o antropólogo. A cultura é ampla, rompe fronteiras, expande o universo em que está inserida; a arte e cultura têm essa característica de ampliar os conhecimentos, na escola é fundamental a multidisciplinaridade, onde a informação e a cultura perpassam as várias disciplinas, agregando conhecimentos que se completam. Nesse contexto, a biblioteca é uma poderosa aliada para essa prática, pois tem como característica essa universalidade de atender a todos, com as mais diversas fontes de informação.

Por volta dos anos de 1980, no Brasil, crescem as discussões em torno da temática da ação cultural, com diversas publicações na área voltadas para as práticas culturais nas bibliotecas e a construção de centros de cultura. Conforme Coelho (2012, p. 9) relata, "Todas as cidades e cidadezinhas brasileiras sonharam primeiro com uma biblioteca. Depois, com um teatro e, mais tarde, um cinema. Em seguida foi a vez dos museus [...]."

Coelho (2012) define a ação cultural ao longo da história em três momentos distintos: em um primeiro momento, as bibliotecas e outras instituições estariam voltadas a preservação dos bens culturais da humanidade. Em um segundo momento, perpassando o século XIX, as instituições culturais voltam o seu interesse para as pessoas, passando a se preocupar mais com os sujeitos que entram em contato com a cultura e a arte do que com o objeto cultural ou artístico em si. No terceiro momento, no final da década de 1960 e, mais especificamente, após 1968, a preocupação não se volta mais ao coletivo, nem com a arte, mas com o individualismo. Os espaços culturais procuram abrir zonas de desenvolvimento para o indivíduo e sua subjetividade. Acredita-se que se está vivenciando o quarto momento da ação cultural, não previsto por Coelho, na época; trata-se do momento da ação cultural voltada à coletividade, em que muitos falam para muitos, por meio da cibercultura, das redes sociais na internet. 
Revista ACB: Biblioteconomia em Santa Catarina, Florianópolis, v. 22, n. 2, ESPECIAL, p. 180-191, abr./ jul., 2017. Anais do $35^{\circ}$ Painel Biblioteconomia Santa Catarina.

Chapecó

Baratin e Jacob (2008, p. 15) destacam que "O poder das bibliotecas reside, enfim, em seu papel crucial na transmissão da cultura e dos saberes". A história das bibliotecas é também a história da sociedade, sendo que a biblioteca é um local de continuidade e de rupturas de tradições. Exemplo disso são as mudanças tecnológicas, tanto do livro, que, de papiro passou a pergaminho, do manuscrito para o impresso e do impresso para o e-book, como dos instrumentos de acesso à leitura, os quais possibilitam mais mobilidade e menos linearidade. Na afirmação dos autores, "A história das bibliotecas, desde as salas de arquivos dos palácios orientais até as bases de dados acessíveis on-line pela internet, é também uma metamorfose dos leitores e das leituras, das políticas de domínio e de comunicação da informação.” (BARATIN; JACOB 2008, p. 11).

A cultura do século XXI é marcada pela presença das redes e das tecnologias digitais de informação e comunicação, permeando as atividades do cotidiano. No século XX, surge a era do broadcast, modelo verticalizado em que um falava para muitos, representado pelo rádio, TV, mensagens de celular e e-mail, e hoje muitos falam para muitos, representados pela internet, por meio do YouTube, sendo que qualquer indivíduo, tendo acesso a rede, pode criar um canal e ter inscritos que acompanham seus vídeos. Outra opção são os Blogs, aplicativos de conversa e as redes sociais como: Facebook, Instagram, Skype, Baidu, Tumbrl, QZone, Wechat, Viber, Twitter, Linkedin e outros. O estudioso da cibercultura e ciberespaço Levy (1999, p. 17) conceitua:

O ciberespaço (que também chamarei de "rede") é o novo meio de comunicação que surge da
interconexão mundial dos computadores. O termo especifica não apenas a infra-estrutura material
da comunicação digital, mas também o universo oceânico de informações que ela abriga, assim
como os seres humanos que navegam e alimentam esse universo. Quanto ao neologismo
"cibercultura", especifica aqui o conjunto de técnicas (materiais e intelectuais), de práticas, de
atitudes, de modos de pensamento e de valores que se desenvolvem juntamente com o crescimento
do ciberespaço.

Os novos paradigmas resultantes do surgimento das tecnologias digitais, da internet e das redes, revolucionaram formatos midiáticos, valores, poder e práticas socioculturais e subverteram as noções de espaço e tempo. Identificando a emergência de uma nova cultura e sinalizando sua potência transformadora, Levy (1999, p. 247) afirma que “[...] longe de ser uma subcultura dos fanáticos pela rede, a cibercultura expressa uma mutação fundamental da própria essência da cultura.”

As novas formas de sociabilidade promovidas pelas tecnologias da comunicação e informação promovem uma reflexão nos modelos e práticas utilizados pelos bibliotecários, suscitando novos desafios em sua atuação, como o distanciamento do público em relação à biblioteca física, que pode ser revertido com a ação e a mediação cultural, desde que promovam a atuação da biblioteca nos diversos meios e realizem atividades culturais também fora das paredes, nas praças, nos shoppings, nas escolas, nas comunidades. Além disso, é possível aliar outras formas de aproximação e fidelização do público, como 
Revista ACB: Biblioteconomia em Santa Catarina, Florianópolis, v. 22, n. 2, ESPECIAL, p. 180-191, abr./ jul., 2017. Anais do $35^{\circ}$ Painel Biblioteconomia Santa Catarina.

Chapecó

por meio de conteúdos na internet, que viabilizem a interação com os usuários nas redes e em aplicativos de comunicação.

A ação cultural possibilita que a biblioteca seja um instrumento de afirmação de expressões artísticas e culturais locais. Enquanto centro cultural acaba ocorrendo uma apropriação da biblioteca como um espaço público da comunidade, que passa a enxergá-la como um ambiente democrático de expressão. Isso fomenta a participação efetiva nas atividades culturais, a utilização da internet na biblioteca, bem como da estrutura física de forma geral, como uma espécie de coworking 5 , oferecendo espaços colaborativos. Isso pode ser oportunizado até mesmo com uma mesa bem iluminada, uma sala, um miniauditório, possibilitando aos profissionais compartilharem seus conhecimentos. Enquanto espaço público, a coexistência de atributos analógicos e digitais fortalece o vínculo dos usuários com a biblioteca, pois os ambientes físico e virtual se encontram interligados e podem ser acessados remotamente nos computadores pessoais, no celular, enfim, no ciberespaço.

\section{A AÇÃO CULTURAL E O CURRÍCULO DOS CURSOS DE BIBLIOTECONOMIA DO RS}

O agente cultural é o profissional que faz o intermédio entre a cultura e o indivíduo, o qual, por si só, faz uso da cultura e cria seus próprios fins. Coelho (1997, p. 31) afirma que: "Para efetivar-se, a ação cultural recorre a agentes culturais previamente preparados e leva em conta públicos determinados, procurando fazer uma ponte entre esse público e uma obra de cultura ou arte.” Ao se deparar com o mercado de trabalho, podem surgir desafios que vão exigir maior dedicação dos profissionais que não tiveram o alicerce da ação cultural em sua formação.

Reconhecendo que o agente cultural é o mediador da cultura, cabe questionar: Na qualidade de bacharéis em biblioteconomia, os bibliotecários estão preparados para exercer o papel de mediadores culturais? A academia prepara esses estudantes de biblioteconomia e futuros profissionais para trabalhar como mediadores e produtores culturais?

$\mathrm{Na}$ busca de respostas a esses questionamentos, foi realizada uma investigação para verificar a existência da ação cultural como disciplina na matriz curricular dos cinco cursos de Biblioteconomia do RS. Inicialmente, conforme já dito anteriormente, no intuito de conhecer as instituições que ofertam o curso de Biblioteconomia no RS, foi realizada uma pesquisa, no site do Ministério da Educação, Brasil (2017), no e-Mec.

\footnotetext{
${ }^{5}[\ldots]$ consiste na partilha de espaços de trabalho por diversos profissionais, na sua maioria com características empreendedoras, que, embora trabalhando de forma independente, partilham valores e trocam ideias e experiências entre si. A partilha não é puramente económica, numa lógica de economia de escala, mas também de experiências e de colaboração laboral. Daí que os valores preconizados pelos espaços de coworking sejam a responsabilidade social, o empreendedorismo, a criatividade e inovação, a colaboração e partilha, e a diversão (CEFADAL, [2012], p.70).

Revista ACB: Biblioteconomia em Santa Catarina, Florianópolis (Brasil) - ISSN 1414-0594
} 
Revista ACB: Biblioteconomia em Santa Catarina, Florianópolis, v. 22, n. 2, ESPECIAL, p. 180-191, abr./ jul., 2017. Anais do $35^{\circ}$ Painel Biblioteconomia Santa Catarina.

Chapecó

Após está identificação, foi realizada pesquisa nas matrizes curriculares disponíveis nos sites dos cursos de Biblioteconomia das universidades do Rio Grande do Sul: Universidade Federal do Rio Grande do Sul (UFRGS) que oferece o curso na modalidade presencial, na capital do estado, Porto Alegre; Fundação Universidade Federal do Rio Grande (FURG), modalidade presencial, na cidade de Rio Grande; Centro Universitário Claretiano (CEUCLAR), modalidade a distância, oferece o curso nos polos de Pelotas e Porto Alegre; Universidade de Caxias do Sul (UCS), modalidade a distância, em Caxias do Sul e Universidade Salgado de Oliveira (UNIVERSO), modalidade a distância, oferta o curso nos polos de Passo Fundo e Uruguaiana.

Abaixo, o quadro 1 com os dados da pesquisa, trazendo o nome da instituição que oferta o curso de Biblioteconomia, o site do curso, o nome da disciplina de ação cultural, tal como consta na matriz curricular, a carga horária destinada à disciplina e o caráter.

Quadro 1 - Instituições do RS que ofertam a disciplina de ação cultural nos cursos de Biblioteconomia

\begin{tabular}{|c|c|c|c|c|}
\hline Instituição & Sítio eletrônico do curso & $\begin{array}{l}\text { Nome da } \\
\text { disciplina }\end{array}$ & $\begin{array}{c}\text { Carga } \\
\text { horária }\end{array}$ & Caráter \\
\hline $\begin{array}{l}\text { Universidade } \\
\text { Federal do Rio } \\
\text { Grande do Sul } \\
\text { (UFRGS) }\end{array}$ & http://www.ufrgs.br/fabico/ & $\begin{array}{l}\text { Ação cultural } \\
\text { em } \\
\text { bibliotecas }\end{array}$ & $\begin{array}{l}3 \\
\text { créditos } \\
45 \mathrm{~h}\end{array}$ & Eletiva \\
\hline $\begin{array}{l}\text { Fundação } \\
\text { Universidade } \\
\text { Federal do Rio } \\
\text { Grande } \\
\text { (FURG) }\end{array}$ & http://www.biblioteconomia.furg.br/ & $\begin{array}{l}\text { Ação } \\
\text { cultural: } \\
\text { teoria e } \\
\text { prática }\end{array}$ & $\begin{array}{l}3 \\
\text { créditos } \\
45 \mathrm{~h}\end{array}$ & Optativa \\
\hline $\begin{array}{l}\text { Centro } \\
\text { Universitário } \\
\text { Claretiano } \\
\text { (CEUCLAR) }\end{array}$ & $\begin{array}{l}\text { https://claretiano.edu.br/graduacao/bibliotecono } \\
\underline{\text { mia }}\end{array}$ & $\begin{array}{l}\text { Ação } \\
\text { cultural: } \\
\text { projetos } \\
\text { culturais e } \\
\text { atuação do } \\
\text { bibliotecário }\end{array}$ & $\begin{array}{l}4 \\
\text { créditos } \\
60 \mathrm{~h}\end{array}$ & $\begin{array}{l}\text { Não há essa } \\
\text { informação }\end{array}$ \\
\hline $\begin{array}{l}\text { Universidade } \\
\text { de Caxias do } \\
\text { Sul (UCS) }\end{array}$ & https://www.ucs.br/portais/curso218/ & $\begin{array}{l}\text { Práticas } \\
\text { culturais }\end{array}$ & $\begin{array}{l}4 \\
\text { créditos } \\
60 \mathrm{~h}\end{array}$ & $\begin{array}{l}\text { Não há essa } \\
\text { informação }\end{array}$ \\
\hline $\begin{array}{l}\text { Universidade } \\
\text { Salgado de } \\
\text { Oliveira } \\
\text { (UNIVERSO) }\end{array}$ & $\begin{array}{l}\text { http://online.universo.edu.br/polos/bibliotecono } \\
\underline{\text { mia/ }}\end{array}$ & Ação cultural & $\begin{array}{l}3 \\
\text { créditos } \\
45 \mathrm{~h}\end{array}$ & $\begin{array}{l}\text { Não há essa } \\
\text { informação }\end{array}$ \\
\hline
\end{tabular}

Fonte: Elaborado pelas autoras deste artigo, com base nos sites dos cursos (2017). 
Revista ACB: Biblioteconomia em Santa Catarina, Florianópolis, v. 22, n. 2, ESPECIAL, p. 180-191, abr./ jul., 2017. Anais do $35^{\circ}$ Painel Biblioteconomia Santa Catarina.

Chapecó

Analisando os dados obtidos nas ementas disponíveis nos sites dos cursos, chega-se à constatação de que todas as instituições que possuem o curso de biblioteconomia do RS estão ofertando a disciplina de ação cultural, mesmo com denominações diferentes, mas em todas são desenvolvidos conteúdos voltados à ação cultural, demonstrando que, no Plano Pedagógico do Curso, há uma visão da necessidade da disciplina para a formação do futuro bibliotecário.

Observou-se também que, nas duas instituições que oferecem o curso na modalidade presencial, a ação cultural não exerce o papel de protagonista, ficando relegada à categoria de disciplinas optativas. Nos três cursos, onde a modalidade é a distância, não foi possível verificar se a ação cultural é ofertada como disciplina obrigatória ou optativa, pois não há esse dado na matriz curricular. Acredita-se na importância da oferta de disciplinas como a Ação cultural, uma vez que são dotadas de conteúdos de grande relevância social para a democratização da cultura e das bibliotecas.

A presença de disciplinas de caráter humanístico é importante, para alicerçar e embasar o trabalho do futuro profissional ao se deparar com as exigências do mercado de trabalho, o qual vai além das atividades técnicas. Os bibliotecários têm que assumir, nas bibliotecas brasileiras, cenários complexos que compreendem ações como: preservar a memória coletiva de um povo; incentivar a leitura; promover espaços de diálogo na e para a comunidade; trabalhar temáticas do mundo contemporâneo, como: a diversidade, o meio ambiente, os direitos humanos e a crise dos refugiados; dar suporte a atividades escolares, acadêmicas e laborais; proporcionar momentos de cultura e lazer, entre outras medidas que exigem do profissional uma formação que estimule o desenvolvimento de habilidades voltadas às práticas socioculturais.

A Associação Brasileira de Educação em Ciência da Informação - ABECIN (2001) destaca os aspectos que convergem para a formação de alunos com visão científica e clareza no reconhecimento da dimensão social da profissão de bibliotecário, bem como da atuação solidária, a fim de modificar o meio em que se insere, de modo a reduzir desigualdades compreendendo e atuando junto às diversidades socioculturais.

É importante que na formação universitária do bibliotecário as grades curriculares dos cursos de Biblioteconomia contemplem conteúdos que possam trazer um equilíbrio entre a parte técnica e a humanística, formando, além de profissionais, cidadãos críticos e reflexivos que, com a sua formação possam cooperar tanto no contexto local como global repensando, assim, a maneira de melhor contribuir com as demandas sociais, sobretudo na era da informação.

Para elucidar a relevância e a necessidade de disciplinas de caráter humanístico, como a Ação Cultural, foram consultadas as diretrizes Curriculares Nacionais para os Cursos de Biblioteconomia que ressaltam: "Recomenda-se que os projetos acadêmicos acentuem a adoção de uma perspectiva 
Revista ACB: Biblioteconomia em Santa Catarina, Florianópolis, v. 22, n. 2, ESPECIAL, p. 180-191, abr./ jul., 2017. Anais do $35^{\circ}$ Painel Biblioteconomia Santa Catarina.

Chapecó

humanística na formulação de conteúdos, conferindo-lhes um sentido social e cultural que ultrapasse os aspectos utilitários mais imediatos sugeridos por determinados itens" (BRASIL, 2011, p. 33).

Nesta perspectiva, acrescenta-se a transcrição de um depoimento de uma aluna, publicado em um artigo do XVII Encontro Regional de Estudantes de Biblioteconomia, realizado no Ceará em 2014:

\begin{abstract}
O interesse em pesquisar a temática da ação cultural em biblioteca é oriundo das discussões e questionamentos ocorridos na disciplina optativa de Ação Cultural cursada por uma das autoras do trabalho no semestre de 2012.2. Essa disciplina em especial chamou a atenção por tratar de uma temática diferente e pouco explorada em outras disciplinas, bem como por, no decorrer da mesma, termos percebido as muitas possibilidades oferecidas pela ação cultural (SILVA; SANTOS, 2014, p. 2).
\end{abstract}

Em seu relato sobre a realização das atividades culturais, na biblioteca da Universidade Federal de Pernambuco (UFPE), Oliveira (2010, p. 9) cita dificuldades encontradas, algumas em relação à falta de conhecimentos sobre a ação cultural: “[...] entendimentos divergentes no que vem a ser a ação cultural, falta de habilidades específicas nos membros que compõem a equipe”.

Na afirmação da autora, é demonstrado o despreparo do bibliotecário e sua equipe, para organizar ações culturais, muitas vezes, por desconhecimento dos pressupostos teóricos do que vem a ser ação cultural, fator esse ocasionado por uma formação voltada às atividades técnicas da profissão. Oliveira (2010, p. 5) afirma também que é preciso ter algumas habilidades e competências: “É necessário ser proativo, lidar com imprevistos, ter criatividade, cultura geral, sensibilidade, trabalhar com profissionais de outras áreas, buscar parceiros, ter uma equipe envolvida e altamente comprometida, do contrário todo esforço será inútil."

Acredita-se que a tendência é de que, cada vez mais, instituições que ofertam os cursos de Biblioteconomia insiram a Ação cultural, enquanto disciplina de seus currículos, devido ao aumento do interesse dos bibliotecários, nessa temática. De acordo com Santos (2015, p.183), “[ [...] nos últimos dez anos percebe-se um aumento no número de publicações sobre ação cultural bibliotecária.” É notável o aumento do volume de publicações em relação ao tema, em artigos de periódicos e anais de eventos, porém a Biblioteconomia ainda necessita, como relatado neste artigo, de maior expressividade, no que tange a disciplinas voltadas para o lado humanístico da profissão, pois todo o trabalho desenvolvido pelas bibliotecas e serviços oferecidos são para as pessoas, o público usuário da informação, tendo os bibliotecários como mediadores da informação e agentes culturais. 
Revista ACB: Biblioteconomia em Santa Catarina, Florianópolis, v. 22, n. 2, ESPECIAL, p. 180-191, abr./ jul., 2017. Anais do $35^{\circ}$ Painel Biblioteconomia Santa Catarina.

Chapecó

\section{CONSIDERAÇÕES FINAIS}

O conceito de cultura é muito amplo e está marcado por diversas concepções tão variadas quanto a diversidade cultural que permeia a sociedade. Os costumes, as crenças e a arte vão se modificando com o passar do tempo, a cultura tem essa característica de expansão, de liberdade. A cibercultura oriunda da internet traz mudanças nas formas de trabalhar, de relacionar-se, de ter sociabilidade, de acesso à informação, proporcionado pela existência do ciberespaço.

Por meio da ação cultural são criadas oportunidades para os indivíduos se expressarem criativa e criticamente. Assim, cabe ao bibliotecário, no papel de agente cultural, a organização das atividades culturais e sua mediação, sem manipulação, possibilitando que o próprio usuário defina os fins que levam a sua prática cultural.

Com a pesquisa e análise dos currículos dos cursos de Biblioteconomia do Rio Grande do Sul, percebe-se que os cinco cursos que constituíram o corpus da pesquisa, da qual resultou este artigo, têm em seus currículos disciplina voltada à ação cultural, mesmo que em alguns seja de caráter opcional, eletivo e/ou com denominações diferentes. Dessa forma, é demonstrada a importância do caráter humanístico ao lado da abordagem técnica, na formação profissional do bibliotecário, preocupação científica que norteou o presente texto, especialmente no que diz respeito àqueles profissionais que desejam ser agentes culturais transformadores na sua atuação em bibliotecas.

A biblioteca do século XXI não pode adotar uma postura passiva, em que os profissionais da equipe não tomam posição frente aos desafios da profissão. A ação cultural é um desafio, assim como a presença de bibliotecas físicas, em tempos em que a internet é a protagonista. Navegar é fundamental e, a partir do momento em que se tem como consolidado o acesso remoto, faz-se necessário navegar para não cair no esquecimento, pois pertencer à sociedade da informação é estar presente na vida do usuário, nas redes sociais, é promover a ação cultural fora das paredes da biblioteca.

\section{REFERÊNCIAS}

ABECIN. Projeto Pedagógico e avaliação da graduação: referências para a renovação e ressignificação do ensino em Biblioteconomia/Ciência da Informação. São Paulo: USP, 2001. Disponível em: http://abecin.org.br/data/documents/Documentos_ABECIN_1.pdf. Acesso em: 29 abr. 2017.

BARATIN, Marc; JACOB, Christian. O poder das bibliotecas: a memória dos livros no ocidente. 3.ed. Rio de Janeiro: Ed. UFRJ, 2008.

BAUMAN, Zygmunt. Ensaios sobre o conceito de cultura. Rio de Janeiro: Zahar, 2012.

BORBA, Francisco S. (Org.) Dicionário UNESP do português contemporâneo. Curitiba: Piá, 2011. 
Revista ACB: Biblioteconomia em Santa Catarina, Florianópolis, v. 22, n. 2, ESPECIAL, p. 180-191, abr./ jul., 2017. Anais do $35^{\circ}$ Painel Biblioteconomia Santa Catarina.

Chapecó

BRASIL. Ministério da Educação. E-mec. Brasília: Mec, 2017. Disponível em: <http://emec.mec.gov.br>. Acesso em: 31 jan. 2017.

. Diretrizes Curriculares Nacionais dos cursos de Filosofia, História, Geografia, Serviço Social, Comunicação Social, Ciências Sociais, Letras, Biblioteconomia, Arquivologia e Museologia. Parecer No: CNE/CES 492/2001. Disponível em: http://portal.mec.gov.br/cne/arquivos/pdf/CES0492.pdf. Acesso em: 28 abr. 2017.

CENTRO UNIVERSITÁRIO CLARETIANO. Curso de biblioteconomia - matriz curricular. Porto Alegre: CEUCLAR, [2016]. Disponível em: <https://claretiano.edu.br/graduacao/biblioteconomia/portoalegre/encontro-uma-vez-por-mes-aos-sabados>. Acesso em: 07 fev. 2017.

COELHO, Teixeira. Dicionário crítico de política cultural: cultura e imaginário. São Paulo: Iluminuras, 1997.

. O que é ação cultural. São Paulo: Brasiliense, 2012.

CEFADAL (CURSO DE ESTUDOS E FORMAÇÃO PARA ALTOS DIRIGENTES DA

ADMINISTRAÇÃO LOCAL), 2012/2013, Coimbra. O agora das bibliotecas ou a biblioteca ágora: bibliotecas públicas, coworking e inovação. Coimbra: Fundação CEFA, [2012]. 110 p. Disponível em: <http://eprints.rclis.org/20485/1/Biblioteca-agora.pdf>. Acesso em: 22 jan. 2017.

FLUSSER, Victor. A biblioteca como um instrumento de ação cultural. Revista Escola de

Biblioteconomia UFMG. Belo Horizonte, v. 12, n. 2, p. 145-169, set. 1983. Disponível em: <http://basessibi.c3sl.ufpr.br/brapci/index.php/article/download/15776>. Acesso em: 28 jan. 2017.

FREUD, Sigmund. O mal-estar na cultura. Rio de Janeiro: L\&PM Pocket, 2010.

FUNDAÇÃO UNIVERSIDADE FEDERAL DO RIO GRANDE. Projeto pedagógico do curso de biblioteconomia da FURG. Rio Grande: FURG, 2015.

LARAIA, Roque de Barros. Cultura: um conceito antropológico. Rio de Janeiro: Zahar, 1986.

LÉVY, Pierre. Cibercultura. São Paulo: Editora 34, 1999.

OLIVEIRA, Luiza M. P. Ação cultural na biblioteca universitária: a experiência da biblioteca central da UFPe. In: SEMINÁRIO NACIONAL DE BIBLIOTECAS UNIVERSITÁRIAS, 16, 2010, Rio de Janeiro. Anais... Rio de Janeiro: UFRJ, 2010.

SANTOS, José Luiz dos. O que é cultura. São Paulo: Brasiliense, 2009.

SANTOS, Josiel Machado. Ação cultural em bibliotecas públicas: o bibliotecário como agente transformador. RBBD Revista Brasileira de Biblioteconomia e Documentação. São Paulo, v.11, n. 2, p. 173-189, jun./dez. 2015. Disponível em: https://rbbd.febab.org.br/rbbd/article/view/425/468. Acesso em: 29 abr. 2017.

SILVA, Maria Mônica da; SANTOS, Izabel Lima dos. Ações culturais em bibliotecas: conceitos e considerações. In: Encontro Regional dos Estudantes de Biblioteconomia, Documentação, Ciência e Gestão da Informação - EREBD Fortaleza (17, fev. 2014). Anais... Fortaleza: UFC, 2014.

TOSCANO, Moema. Introdução à sociologia educacional. Petrópolis: Vozes, 2010. 
Revista ACB: Biblioteconomia em Santa Catarina, Florianópolis, v. 22, n. 2, ESPECIAL, p. 180-191, abr./ jul., 2017. Anais do $35^{\circ}$ Painel Biblioteconomia Santa Catarina.

Chapecó

UNIVERSIDADE DE CAXIAS DO SUL. Biblioteconomia EAD- Plano curricular. Caxias do Sul: UCS, [2009]. Disponível em: https://www.ucs.br/portais/curso218/plano/GRA000905/AV/. Acesso em: 08 fev. 2017.

\title{
UNIVERSIDADE FEDERAL DO RIO GRANDE DO SUL. Projeto pedagógico do curso de
}

biblioteconomia. Porto Alegre: UFRGS, 2012. Disponível em: <http://www.ufrgs.br/fabico/documentosgraduacao-e-comgrads/projeto-pedagogico-do-curso-de-biblioteconomia>. Acesso em: 07 fev. 2017.

UNIVERSIDADE SALGADO DE OLIVEIRA. Grade e corpo docente: curso de bacharelado em biblioteconomia 2017-1. Disponível em: <http://online.universo.edu.br/wpcontent/uploads/2013/12/GRADEECORPODOCENTE_BIBLIOTECONOMIA_2017_1.pdf >. Acesso em 08 fev. 2017.

\section{THE CULTURAL ACTION IN THE LIBRARIES AND ITS DIMENSION FOR THE 21ST CENTURY SOCIETY}

\begin{abstract}
The present study aims to discuss the cultural action in an emancipatory perspective, converging the discussions to cultural studies, the information society, the cyberculture and cyberspace age, connecting the physical and digital environment. It also aims to verify if the Rio Grande do Sul Library Science courses are preparing the future librarians to act as cultural agents. The methodology used in this research is a qualitative, exploratory, bibliographic approach and documentary analysis of the curricular matrices of the RS Library Science courses. It was verified that the five institutions are offering the discipline of cultural action, even with different denominations. So, it was concluded that there is a view on the part of the researched courses regarding the necessity of the discipline for the formation of the future librarian and cultural actions can be carried out and publicized, using information and communication technologies.
\end{abstract}

Keywords: Cultural action. Libraries. Cyberculture. Curriculum.

Carla Rosane da Silva Tavares Alves - Doutora em Letras pela Universidade Federal do Rio Grande do Sul (UFRGS). Mestra em Letras pela Pontifícia Universidade Católica do Rio Grande do Sul (PUCRS). Graduada em Direito pela Universidade de Cruz Alta (UNICRUZ). Graduada em Letras-Português/Inglês pela Associação de Professores de Cruz Alta (APROCRUZ). Professora Adjunta da Universidade de Cruz Alta.E-mail: ctavares@unicruz.edu.br

Criselen Jarabiza - Mestranda em Práticas Socioculturais e Desenvolvimento Social pela Universidade de Cruz Alta (UNICRUZ). Especialista MBA em Gestão de Recursos Humanos pela Faculdade de Tecnologia de Curitiba (FATEC). Graduada em Biblioteconomia pela Universidade Federal de Rio Grande (FURG). Email: crysbiblio@yahoo.com.br 